\title{
ILHAS DE CALOR SUPERFICIAIS: FREQUÊNCIA DA INTENSIDADE E VARIABILIDADE ESPACIAL EM CIDADE DE CLIMA TROPICAL CONTINENTAL
}

\author{
SURFACE HEAT ISLANDS: FREQUENCY OF SPATIAL INTENSITY AND VARIABILITY IN A CITY WITH A \\ CONTINENTAL TROPICAL CLIMATE
}

\author{
Margarete Cristiane de Costa Trindade Amorim ${ }^{1}$ \\ 1 Universidade Estadual Paulista (UNESP), Presidente Prudente, SP, Brasil \\ Correspondência para: Margarete Cristiane de Costa Trindade Amorim (margarete.amorim@unesp.br) \\ doi: 10.12957/geouerj.2019.40959 \\ Recebido em: 17 ago. 2018 | Aceito em: 09 out. 2018
}

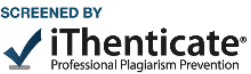

\section{RESUMO}

Este artigo teve como objetivo analisar a distribuição espacial das temperaturas dos alvos e a frequência de intensidades das ilhas de calor superficiais em áreas com diferentes características de uso da terra, de cobertura vegetal, de densidade de edificação e de padrão construtivo de habitação, em Presidente Prudente/SP. Os procedimentos adotados consistiram na utilização de 24 imagens do satélite Landsat 8, banda 10, disponíveis e sem cobertura de nuvens entre fevereiro de 2013 e janeiro de 2016. Os resultados mostraram que a maior frequência de altas intensidades de ilhas de calor superficiais foi registrada em conjunto habitacional de baixo padrão construtivo, seguido por bairro de médio padrão construtivo. As áreas com menor densidade construtiva e presença de solos permeáveis com cobertura vegetal rasteira e arbórea foram as que apresentaram maior frequência de baixas intensidades de ilhas de calor superficiais. A variabilidade espacial das temperaturas das superfícies no ambiente urbano e rural próximo resulta das características físicas dos alvos (tipos de materiais construtivos, impermeabilização do solo, densidade de construções e de vegetação). Estas características, decorrentes do processo de urbanização, podem contribuir para que a população mais pobre e, portanto, mais vulnerável, seja mais suscetível a situações de desconforto térmico e sujeitas a problemas de saúde.

Palavras-chave: ilha de calor de superfície. variabilidade espacial. uso da terra. sensoriamento remoto. Landsat 8.

\begin{abstract}
The purpose of this article was to analyze the spatial distribution of target temperatures and the frequency of surface heat island intensities in areas with characteristics relating to land use, vegetation cover, densities and different construction patterns in Presidente Prudente, SP. The procedures adopted consisted of the use of 24 images of the Landsat 8 satellite, band 10, available and without cloud cover, between February 2013 and January 2016. The results showed that the higher frequency of high intensities of surface heat islands was recorded in a housing complex with a low building standard, followed by a neighborhood with a medium building standard. The areas with the lowest building density and presence of permeable soils with ground cover and tree cover were the ones that presented the highest frequency of low intensities of surface heat islands or fresh islands. The spatial variability of surface temperatures in the neighboring urban and rural environment results from the physical characteristics of the targets (types of building materials, soil waterproofing, density of buildings, and vegetation). These characteristics, resulting from the urbanization process, may cause the poorest, and therefore, most vulnerable, population to be more susceptible to situations of thermal discomfort and health problems.
\end{abstract}

Keywords: surface heat island. spatial variability. land use. remote sensing. Landsat 8.

\section{INTRODUÇÃO}


As ilhas de calor superficiais diagnosticadas por meio do sensoriamento remoto (ARNFIELD, 2003; AMORIM, 2018) resultam da troca de energia entre os alvos urbanos e a atmosfera.

Nos ambientes urbanos a impermeabilização da superfície decorrente da substituição da vegetação por diversos tipos de materiais resulta no aquecimento não apenas dos alvos, gerando as ilhas de calor superficiais, mas também da atmosfera sobre as cidades (MONTEIRO, 1976), produzindo as ilhas de calor atmosféricas. Oke (1978) classificou as ilhas de calor urbanas atmosféricas em dois níveis: a camada de ar compreendida entre a superfície até o nível médio dos telhados, denominada como urban canopy layer e acima do nível médio dos telhados, conhecida como urban boundary layer.

As imagens de satélite têm ampliado as possibilidades de análise das ilhas de calor urbanas, especialmente as superficiais, porque fornecem a temperatura aparente da superfície (Land Surface Temperature - LST), propiciando visões em diferentes escalas do desenho da temperatura local (WENG, 2003). O desenvolvimento de satélites com alta resolução espacial tem contribuído para 0 aumento de estudos sobre este tema, que até recentemente era menos comum no Brasil (AMORIM, 2017a).

Inicialmente a termografia da superfície foi estudada por meio de imagens do satélite NOAA (National Oceanic and Atmospheric Administration), com resolução espacial de 1,1 km (MATSON et al., 1978; KIDDER e WU, 1987; GALLO et al., 1993). No Brasil, Lombardo (1985) realizou estudo pioneiro utilizando-se deste satélite e identificou temperaturas maiores na área urbanizada, mas, devido à resolução espacial da imagem, obteve pouco detalhamento no intraurbano.

Recentemente, diversos estudos foram realizados com imagens do satélite Landsat (Land Remote Sensing Satellite) 5 e 7 (banda 6 do canal infravermelho termal com resoluções espaciais de 120 e 60 metros, respectivamente) e do Landsat 8, bandas 10 e 11, do infravermelho termal/TIRS 1, com resolução espectral de 10.6 - $11.19 \mu \mathrm{m}$ e resolução espacial de 100 metros, mas tratadas e disponibilizadas com pixel de 30 metros pela USGS (United States Geological Survey). 
Tais imagens permitem maior detalhamento das temperaturas dos alvos, devido a sua maior resolução espacial. Este fato favoreceu a realização de vários estudos tanto em cidades brasileiras de grande porte (SOUSA e BAPTISTA, 2005; MENDONÇA e DUBREUIL, 2005; BIAS et al., 2003; ANDRADE et al., 2007; COLTRI et al., 2007; LEMOS, 2011; LUCENA et al., 2013), como em cidades de médio e de pequeno porte (MENDONÇA, 1994; BARBOSA e VECCHIA, 2009; AMORIM et al., 2009; POLIZEL, 2009; DORIGON e AMORIM, 2013; CRUZ, 2009; ARAUJO et al., 2010; AMORIM e MONTEIRO, 2011; FEITOSA et al., 2011; BARROS e LOMBARDO, 2012; UGEDA JUNIOR, 2013; AMORIM, 2013; ORTIZ e AMORIM, 2013; ARAUJO et al., 2016; AMORIM, 2017a; dentre outros).

O maior detalhamento das ilhas de calor superficiais pode contribuir para ações efetivas junto ao planejamento e a gestão dos ambientes urbanos, no sentido de mitigar suas intensidades, com o propósito de amenizar o desconforto térmico para a população em zonas climáticas submetidas a sistemas atmosféricos que naturalmente apresentam temperaturas elevadas, prejudiciais à saúde das pessoas.

Este artigo teve como objetivo analisar a distribuição espacial das temperaturas dos alvos e a frequência de intensidades das ilhas de calor superficiais em áreas com diferentes características de uso da terra, de cobertura vegetal, de densidade de edificação e de padrão construtivo de habitação, em Presidente Prudente/SP.

O município possui população estimada de 225.271 habitantes (IBGE, 2017 - Instituto Brasileiro de Geografia e Estatística) e localiza-se no oeste do estado de São Paulo/Brasil (Figura 1), entre as coordenadas $22^{\circ} 18^{\prime}$ e $22^{\circ} 06^{\prime}$ de latitude sul e $51^{\circ} 47^{\prime}$ e $51^{\circ} 34^{\prime}$ de longitude oeste. 


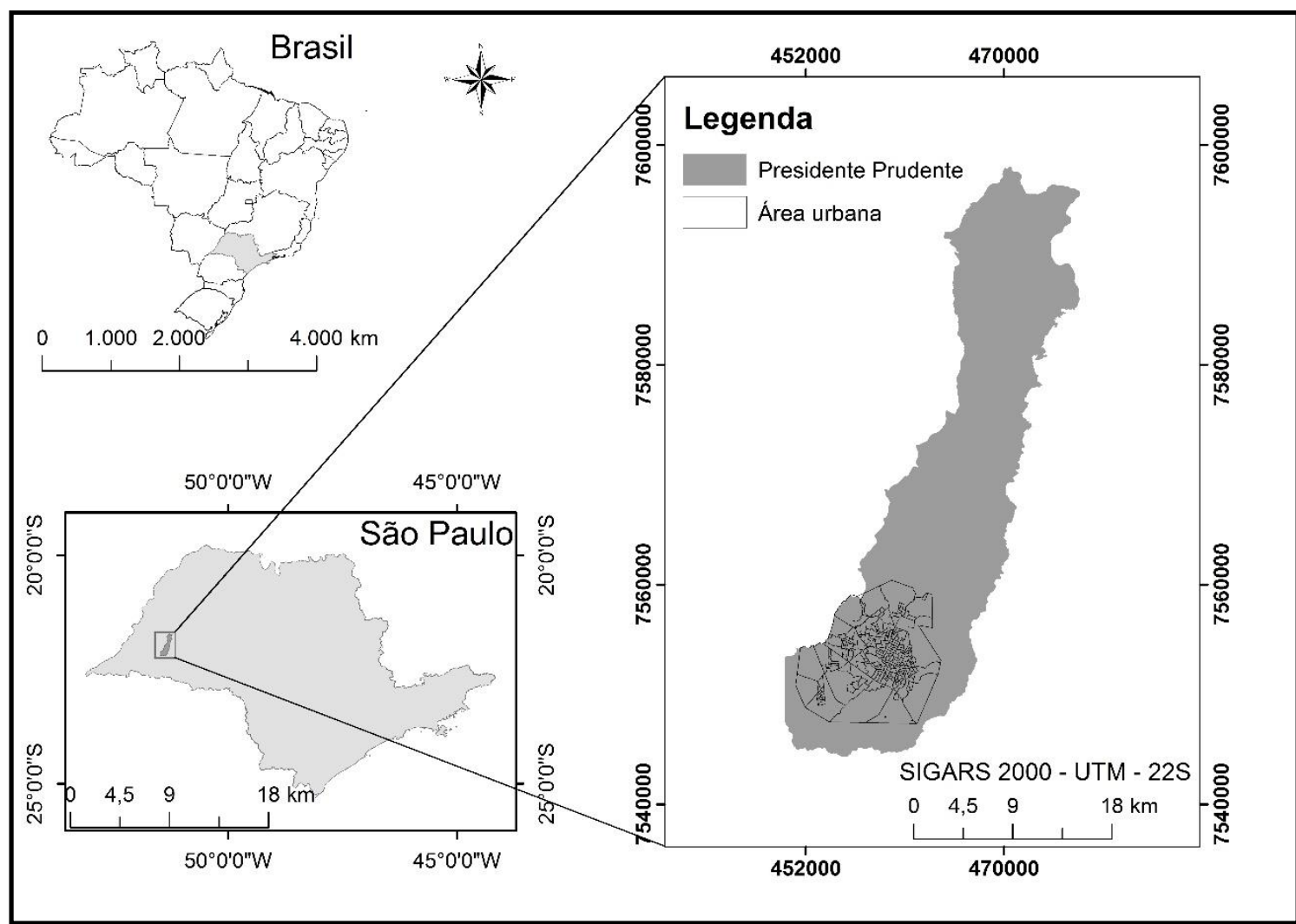

Figura 1. Localização de Presidente Prudente no oeste do estado de São Paulo/Brasil.

Presidente Prudente é capital regional de uma extensa área agropastoril e caracteriza-se como um importante centro de comércio, de serviços e universitário, com setor industrial pouco expressivo quando comparado com outras áreas do estado de São Paulo (SPOSITO, 2011).

Sua área urbana apresenta características diferenciadas no que se refere à cobertura arbórea nas calçadas e no interior dos lotes, na densidade de edificações e no padrão construtivo das habitações. No seu entorno rural próximo há o predomínio de áreas com vegetação rasteira (principalmente pastagem) e alguns fragmentos de vegetação arbórea em fundos de vales. Estas características de uso e ocupação, associadas à morfologia de sua superfície afeta o clima local através da modificação do fluxo e do transporte de calor no ar, enquanto a cobertura da terra modifica o albedo, a disponibilidade de umidade e potencial de aquecimento/resfriamento do solo (AMORIM, 2000 e 2017b; CARDOSO, 2015).

Localizada em área de transição climática entre os sistemas tropicais e extratropicais, Presidente Prudente possui variabilidade interanual acentuada. Os eventos naturais de temperaturas elevadas são 
comuns no município e impactam negativamente a qualidade de vida da população que, em geral, busca em climatizadores de ambiente a saída para amenizar as situações de estresse térmico. Entretanto, o acesso a esses equipamentos é restrito a uma pequena parcela da população que dispõe de recursos para este fim. A maioria das pessoas fica submetida às situações de desconforto que são intensificadas pela geração das ilhas de calor (AMORIM, 2017b).

No período da primavera e do verão, as temperaturas diárias oscilam entre os $20^{\circ} \mathrm{C}$ e $32^{\circ} \mathrm{C}$, com máximas absolutas que podem chegar a $40^{\circ} \mathrm{C}$. Nesta época do ano concentra-se cerca de $75 \%$ da precipitação média anual de $1.300 \mathrm{~mm}$ (AMORIM, 2018). No outono/inverno as temperaturas decrescem ligeiramente, mas permanecem elevadas, à exceção dos episódios das invasões do anticiclone polar, quando as temperaturas mínimas oscilam entre $15^{\circ} \mathrm{C}$ e $20^{\circ} \mathrm{C}$, com valores absolutos que raras vezes se aproxima de $0^{\circ} \mathrm{C}\left(-1,8^{\circ} \mathrm{C}\right.$ em julho de 1975) (AMORIM et al., 2009).

\section{PROCEDIMENTOS METODOLÓGICOS}

Para atingir os objetivos propostos foram utilizadas imagens do satélite Landsat 8, banda 10, do canal infravermelho termal/TIRS 1, com resolução espectral de 10.6 - $11.19 \mu \mathrm{m}$ e resolução espacial de 100 metros, mas tratadas e disponibilizadas com pixel de 30 metros pela United States Geological Survey (USGS) ${ }^{1}$.

As imagens do satélite Landsat 8 , banda 10, disponíveis no período de fevereiro de 2013 a janeiro de 2016, e sem cobertura de nuvens, foram tratadas e totalizaram 24 cenas.

Para se analisar a intensidade $(\Delta \mathrm{T})$ das ilhas de calor superficiais (e não os valores absolutos), foram calculadas as diferenças das temperaturas intraurbanas em relação à área com alta densidade de cobertura vegetal arbórea localizada a nordeste da malha urbana, conhecida como "Mata do Furquim" (Figura 2). Esta área sempre está entre aquelas que apresentam as menores temperaturas dos alvos, devido à presença de quantidade significativa de cobertura vegetal arbórea. Por este motivo foi

\footnotetext{
1 As características dos produtos/imagens são consistentes com o padrão de Nível 1 (ortorretificadas) semelhantes aos da série Landsat 1 ao 7. O formato dos dados disponibilizados pode ser baixado via Internet e constitui um arquivo TXT (metadados) e arquivos GEOTIFF compactados. A resolução radiométrica é de 16 Bits, Datum WGS 1984, projeção UTM (polar estereográfica para a Antártida), sendo necessário reprojetá-las para sul.

${ }^{1}$ Disponibilizadas gratuitamente no site: http://earthexplorer.usgs.gov/
} 
considerada como ponto "0" e, a partir dela, foram calculadas as diferenças de temperaturas dos alvos (por pixel), para que fosse possível reconhecer um padrão de aquecimento predominante nos diferentes tipos de alvos.

Depois de elaborados os 24 mapas de intensidade das temperaturas dos alvos, foi gerado um mapa síntese (Figura 4), calculando-se a média dos pixels das imagens tratadas entre 2013 e janeiro de 2016.

Para se quantificar a frequência de intensidades das ilhas de calor nas 24 imagens analisadas em áreas com características diferentes, foram selecionados 6 pontos, sendo 3 deles do entorno rural próximo e 3 do intraurbano (Figura 2). Para a escolha desses pontos, realizou-se uma análise qualitativa das caraterísticas da superfície e dentre elas destacam-se: a densidade de construções, a vegetação arbórea e rasteira, o tipo de cobertura dos telhados, a altitude e a localização no contexto da malha urbana, por serem estes os principais fatores que interferem nas temperaturas da superfície (Figura 3).

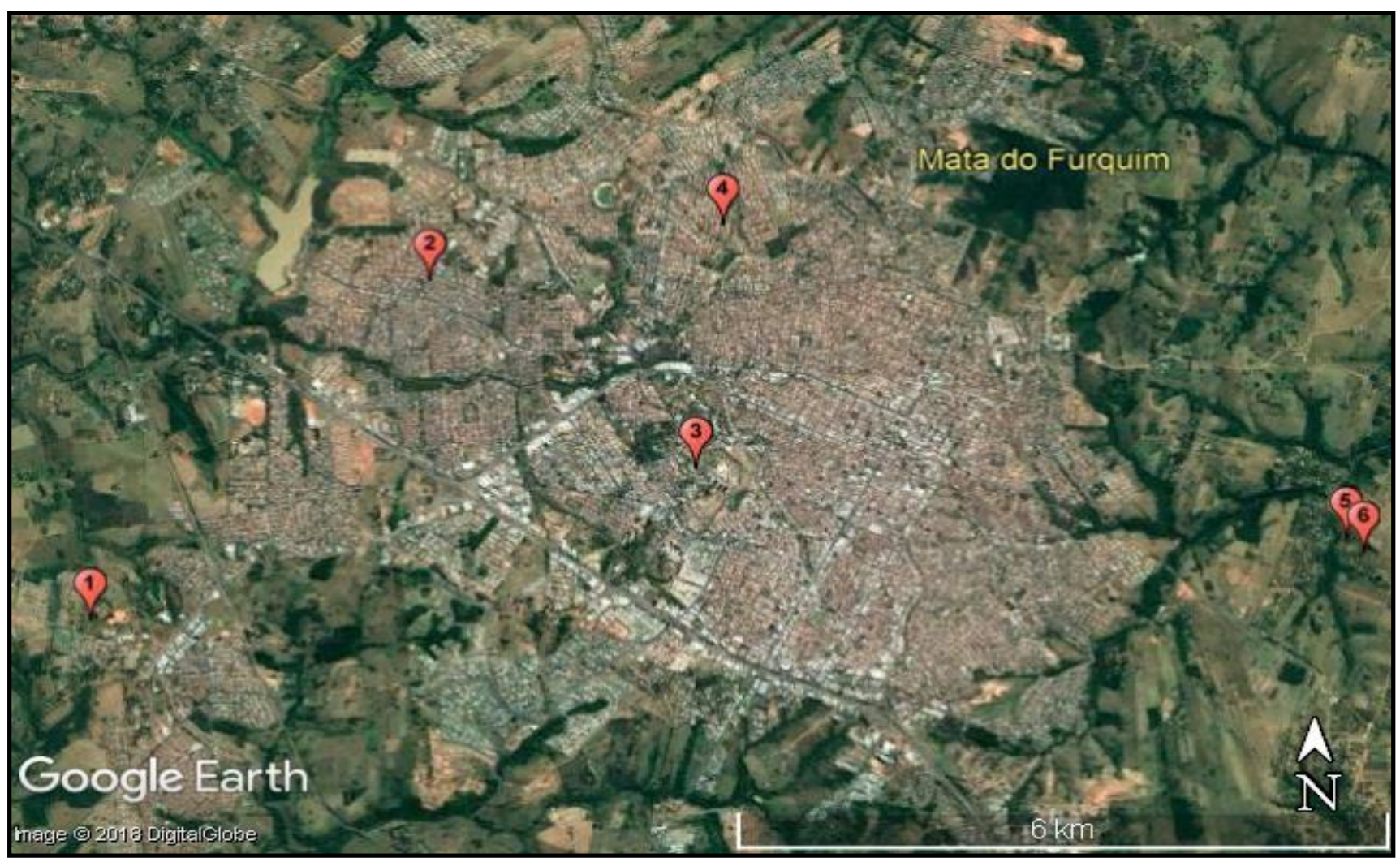

Figura 2. Presidente Prudente: localização da Mata do Furquim a nordeste da malha urbana, utilizada como o ponto "0" para o cálculo da intensidade das ilhas de calor de superfície e pontos (1 a 6 ) utilizados para o cálculo da frequência (\%).Fonte: Google Earth TM mapping service/NASA/Terra Métrics copyright (acesso: agosto de 2018). 


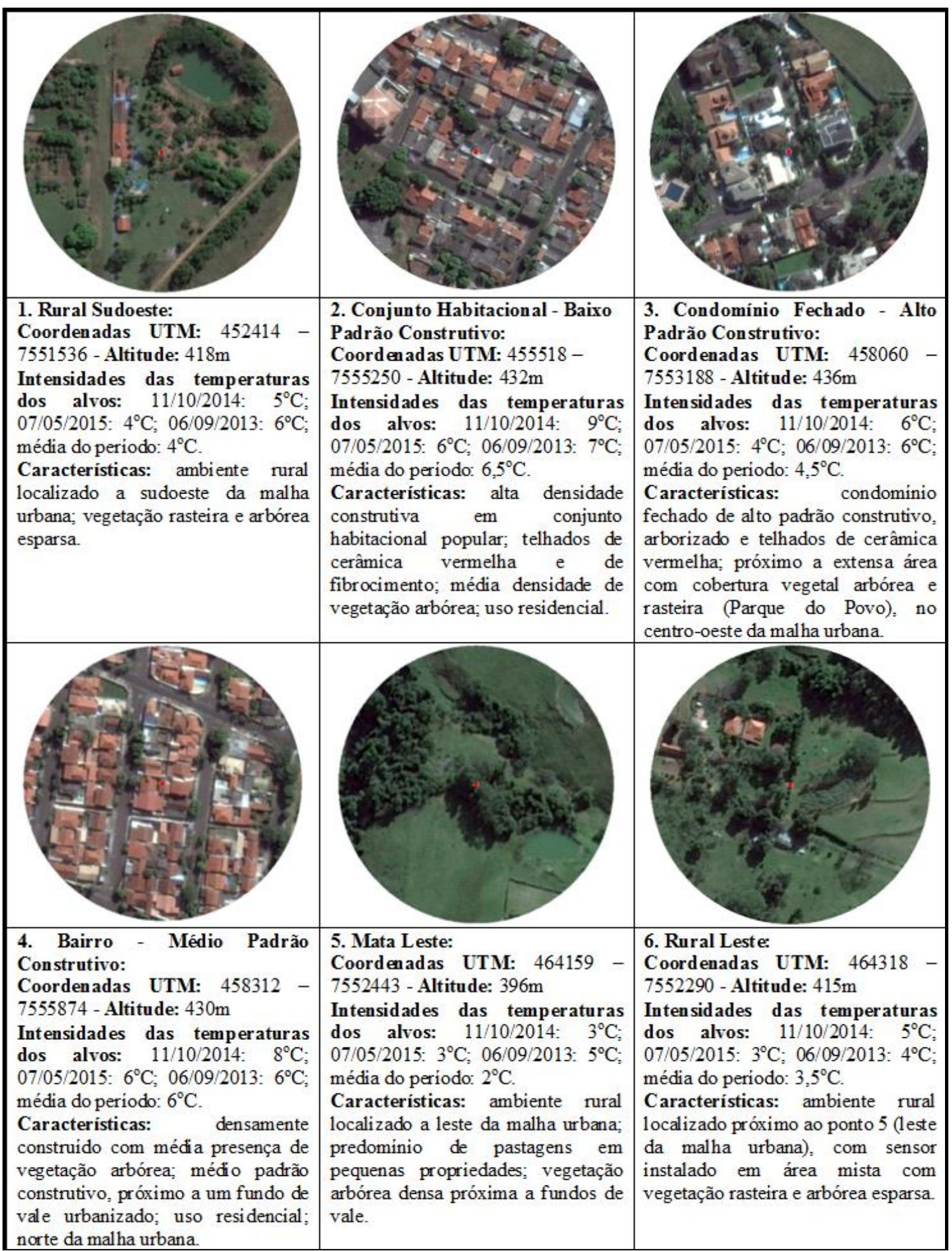

Figura 3. Características do entorno dos pontos utilizados para o cálculo das frequências (\%) das intensidades das ilhas de calor superficiais 
Os procedimentos para a obtenção das temperaturas em Celsius $\left({ }^{\circ} \mathrm{C}\right)$ nas imagens de satélite foram realizados no aplicativo IDRISI ${ }^{2}$, com a utilização de parâmetros fixos de conversão de níveis de cinza da imagem (NC) para radiância, depois para temperatura Kelvin e finalmente para Celsius.

As equações e parâmetros foram obtidos no site da $U_{S G S}^{3}$ e serão apresentados a seguir.

$$
\mathrm{L} \lambda=\mathrm{MLQcal}+\mathrm{AL}
$$

Onde:

$\mathrm{L} \lambda=$ Radiância do topo da atmosfera (Watts/( $\mathrm{m} 2 * \operatorname{srad} * \mu \mathrm{m}))$;

$\mathrm{ML}=$ Fator multiplicativo de redimensionamento de cada banda presente nos metadados (Radiance_Mult_Band_x, onde x é o número da banda);

$\mathrm{AL}=$ Fator aditivo de redimensionamento de cada banda presente nos metadados (Radiance_Add_Band_x, onde x é o número da banda);

Qcal $=$ Valores de pixel quantificados e calibrados do produto padrão (DN).

Na sequência processou-se a correção atmosférica das imagens segundo os princípios disponibilizados pela Atmospheric Correction Parameter Calculator, a qual fornece valores locais para Transmittance, Upwelling Radiance e Downwelling Radiance. Para isso foram incluídos os dados de estação meteorológica do local.

De acordo com Coll et al. (2010), a equação 2 se aplica à correção atmosférica específica da cena.

$$
C V_{R 2}=\frac{C V_{R 1}-L \uparrow}{\varepsilon \tau}-\frac{1-\varepsilon}{\varepsilon} L \downarrow
$$

Onde:

$\mathrm{CV}_{\mathrm{R} 2}$ - valor da célula da correção atmosférica como radiância

$\mathrm{CV}_{\mathrm{R} 1}$ - valor da célula como radiância da seção 1

\footnotetext{
${ }^{2}$ Idrisi é marca registrada da Clark University.

${ }^{3}$ Esses procedimentos foram obtidos no site https://landsat.usgs.gov/Landsat8_Using_Product.php. Acesso em: 07 jun. $\underline{2016 .}$
} 
$\mathrm{L} \uparrow$ - upwelling radiance

$\mathrm{L} \downarrow$ - downwelling radiance

$\tau$ - transmitância

$\mathcal{E}$ - emissividade (0.95).

Fonte: Extraída de Coll et al., 2010.

Após a correção atmosférica, aplicou-se a equação 3 para converter os valores em temperatura Kelvin:

$$
T=\frac{K 2}{\ln \left(\frac{K 1}{L \lambda}+1\right)}
$$

Onde:

T - Temperatura efetiva no satélite em Kelvin;

K2 - Constante de calibração 2 - valor - 1321.08;

K1 - Constante de calibração de 1 - valor - 774.89;

L - Radiância espectral, em Watts/(metro quadrado ster $* * \mathrm{~mm})$.

Fonte: Extraído de USGS, 2015.

Após esses procedimentos, aplicou-se a fórmula para converter a temperatura Kelvin em Celsius. Para gerar a grade de temperatura da superfície em Celsius $\left({ }^{\circ} \mathrm{C}\right)$, os valores de temperatura foram subtraídos de 273,15 .

A delimitação da área onde a cidade está inserida na imagem de satélite foi definida a partir da sobreposição da base cartográfica dos setores censitários do IBGE na cena.

Para a elaboração do mapa síntese das intensidades das temperaturas dos alvos, calculou-se a média dos pixels das 24 imagens tratadas no período de 2013 a janeiro de 2016, no aplicativo IDRISI.

\section{FREQUÊNCIA DA INTENSIDADE DAS ILHAS DE CALOR SUPERFICIAIS E SUA DISTRIBUIÇÃO} ESPACIAL 
Os resultados mostraram que a associação da alta densidade de construções com a menor presença de cobertura vegetal arbórea são os principais fatores responsáveis pelas maiores intensidades nas temperaturas dos alvos.

Analisando-se as frequências das intensidades das temperaturas dos pixels nas 24 imagens tratadas entre 2013 e 2016 (Tabela 1 e Figura 4), em pontos com características de uso e ocupação da terra diferenciados, observa-se que em relação à área densamente arborizada localizada à nordeste da malha urbana (Mata do Furquim), o ponto rural (5) apresentou as menores intensidades das ilhas de calor superficiais. Em 29\% das imagens, as intensidades das temperaturas ficaram abaixo de $0^{\circ} \mathrm{C}$, portanto, com ilhas de frescor ${ }^{4}$ superficiais; em $54 \%$ delas entre $0^{\circ} \mathrm{C}$ e $2{ }^{\circ} \mathrm{C}$, e em $17 \%$ entre $2^{\circ} \mathrm{C}$ e $4^{\circ} \mathrm{C}$ (Tabela 1 e Gráfico 1).

Os outros pontos rurais (1 e 6 ) também apresentaram as maiores frequências das ilhas de calor superficiais entre $0^{\circ} \mathrm{C}$ e $2{ }^{\circ} \mathrm{C}$, com respectivamente $71 \%$ e $67 \%$.

No conjunto habitacional (2), bairro popular com alta densidade construtiva, de baixo padrão, terrenos pequenos, telhados de cerâmica vermelha e de fibrocimento e média densidade de vegetação arbórea (Figura 3), as intensidades das ilhas de calor superficiais ficaram assim apresentadas: 38\% delas foram registradas entre $4^{\circ} \mathrm{C}$ e $6^{\circ} \mathrm{C}, 29 \%$ entre $2^{\circ} \mathrm{C}$ e $4^{\circ} \mathrm{C}, 25 \%$ acima de $6^{\circ} \mathrm{C}$ (entre $8^{\circ} \mathrm{C}$ e $10^{\circ} \mathrm{C}$ ) e apenas $8 \%$ entre $0^{\circ} \mathrm{C}$ e $2{ }^{\circ} \mathrm{C}$.

No bairro de médio padrão construtivo (4), com alta densidade de edificações, média densidade de cobertura vegetal arbórea e telhados de cerâmica vermelha, as intensidades das ilhas de calor ficaram assim apresentadas: $50 \%$ entre $2^{\circ} \mathrm{C}$ e $4^{\circ} \mathrm{C}, 25 \%$ entre $4^{\circ} \mathrm{C}$ e $6^{\circ} \mathrm{C}, 17 \%$ acima de $6^{\circ} \mathrm{C}$ (entre $8^{\circ} \mathrm{C}$ e $\left.10^{\circ} \mathrm{C}\right)$ e $8 \%$ entre $0^{\circ} \mathrm{C}$ e $2^{\circ} \mathrm{C}$.

\footnotetext{
${ }^{4}$ Considera-se "ilha de frescor" quando a intensidade da temperatura do alvo em análise é menor do que a registrada no ponto "0" onde habitualmente se registra a menor temperatura da cena ( no caso do presente estudo trata-se da "Mata do Furquim" - Figura 2).
} 
As intensidades entre $6^{\circ} \mathrm{C}$ e $10^{\circ} \mathrm{C}$ foram registradas no conjunto habitacional de baixo padrão construtivo (2) e no bairro de médio padrão construtivo (4), com respectivamente $25 \%$ e $17 \%$ e não ocorreram nos pontos rurais (1,5 e 6 ) e no condomínio fechado de alto padrão construtivo (3) (Tabela 1 e Gráfico 1).

Deste modo, as áreas com menor densidade construtiva e presença de solos permeáveis com cobertura vegetal rasteira e arbórea no entorno da malha urbana, foram as que apresentaram maior frequência de baixas intensidades de ilhas de calor superficiais ou de ilhas frescas.

\begin{tabular}{|c|c|c|c|c|c|}
\hline Pontos & $\begin{array}{c}\text { IF } \\
\text { (abaixo } \\
\text { de } 0^{\circ} \mathrm{C} \text { ) } \\
-\%\end{array}$ & $\begin{array}{c}\text { IC de fraca } \\
\text { magnitude } \\
\left(\text { entre } 0^{\circ} \mathrm{e}\right. \\
\left.2^{\circ} \mathrm{C}\right)-\%\end{array}$ & $\begin{array}{c}\text { IC de } \\
\text { média } \\
\text { magnitude } \\
\left(\text { entre } 2^{\circ} \mathrm{e}\right. \\
\left.4^{\circ} \mathrm{C}\right)-\% \\
\end{array}$ & $\begin{array}{c}\text { IC de forte } \\
\text { magnitude } \\
\text { (entre } 4^{0} \mathrm{e} \\
\left.6^{\circ} \mathrm{C}\right)-\%\end{array}$ & $\begin{array}{c}\text { IC de } \\
\text { muito forte } \\
\text { magnitude } \\
\text { (acima de } \\
6^{\circ} \mathrm{C} \text { ) - } \%\end{array}$ \\
\hline $\begin{array}{l}\text { 1. Rural } \\
\text { Sudoeste }\end{array}$ & 4 & $\underline{71}$ & 21 & 4 & 0 \\
\hline $\begin{array}{l}\text { 2. Conjunto } \\
\text { Habit acional: } \\
\text { Baixo Padrão } \\
\text { Construtivo }\end{array}$ & 0 & 8 & 29 & $\underline{38}$ & 25 \\
\hline $\begin{array}{l}\text { 3. Condomínio } \\
\text { Fechado: Alto } \\
\text { Padrão } \\
\text { Construtivo }\end{array}$ & 0 & 42 & $\underline{54}$ & 4 & 0 \\
\hline $\begin{array}{l}\text { 4. Bairro: Médio } \\
\text { Padrão } \\
\text { Construtivo }\end{array}$ & 0 & 8 & $\underline{50}$ & 25 & 17 \\
\hline 5. Mat a Leste & 29 & 54 & 17 & 0 & 0 \\
\hline 6. Rural Leste & 13 & $\underline{67}$ & 21 & 0 & 0 \\
\hline
\end{tabular}

Tabela 1. Frequências (\%) das intensidades e magnitudes das ilhas de calor e de frescor superficiais das 24 imagens do satélite Landsat 8, banda 10, de 2013 a janeiro de 2016 - $10 \mathrm{~h} 22$ hora local (IF - Ilha de Frescor; IC - Ilha de Calor). 


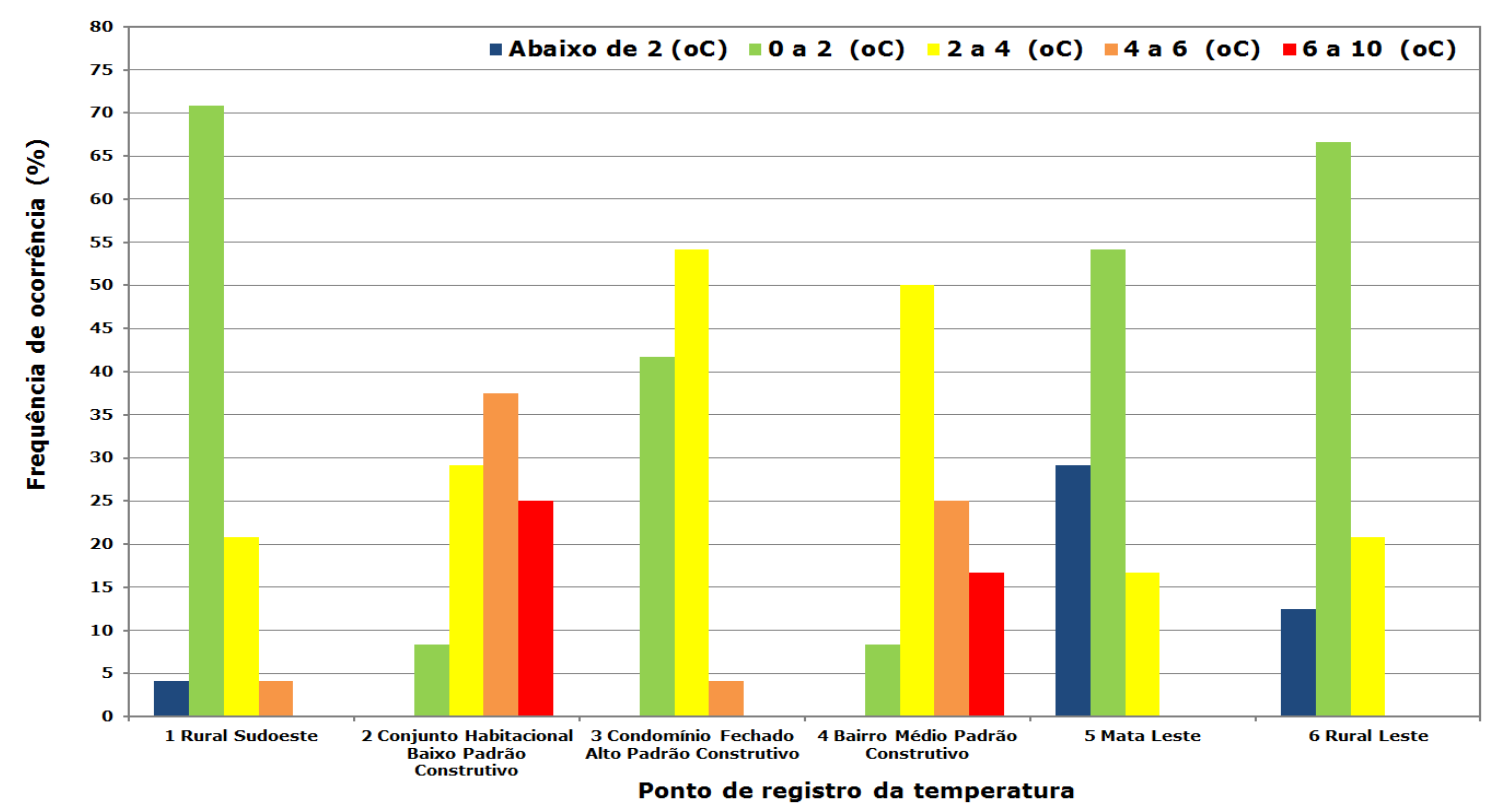

Figura 4. Frequências (\%) das intensidades das ilhas de calor e de frescor superficiais das 24 imagens do satélite Landsat 8 , banda 10, de 2013 a janeiro de 2016 - 10h22 hora local.

No mapa síntese das intensidades das temperaturas dos alvos (Figura 5), verifica-se que as altas intensidades das ilhas de calor superficiais foram registradas em bairros com iguais características do conjunto habitacional de baixo padrão construtivo (2) e dentre eles, destacam-se, os localizados à sudoeste, ao norte e a leste da malha urbana.

Assim, os bairros periféricos de habitações populares, com terrenos pequenos e densamente construídos apresentaram as maiores temperaturas quando comparados com outros que, embora também densamente construídos, possuem cobertura vegetal arbórea nas calçadas e, em alguns casos, no interior dos lotes.

Tais resultados mostram que as temperaturas dos alvos sintetizam a densidade construtiva, de vegetação e o tipo de materiais de cobertura dos telhados (e da superfície). 


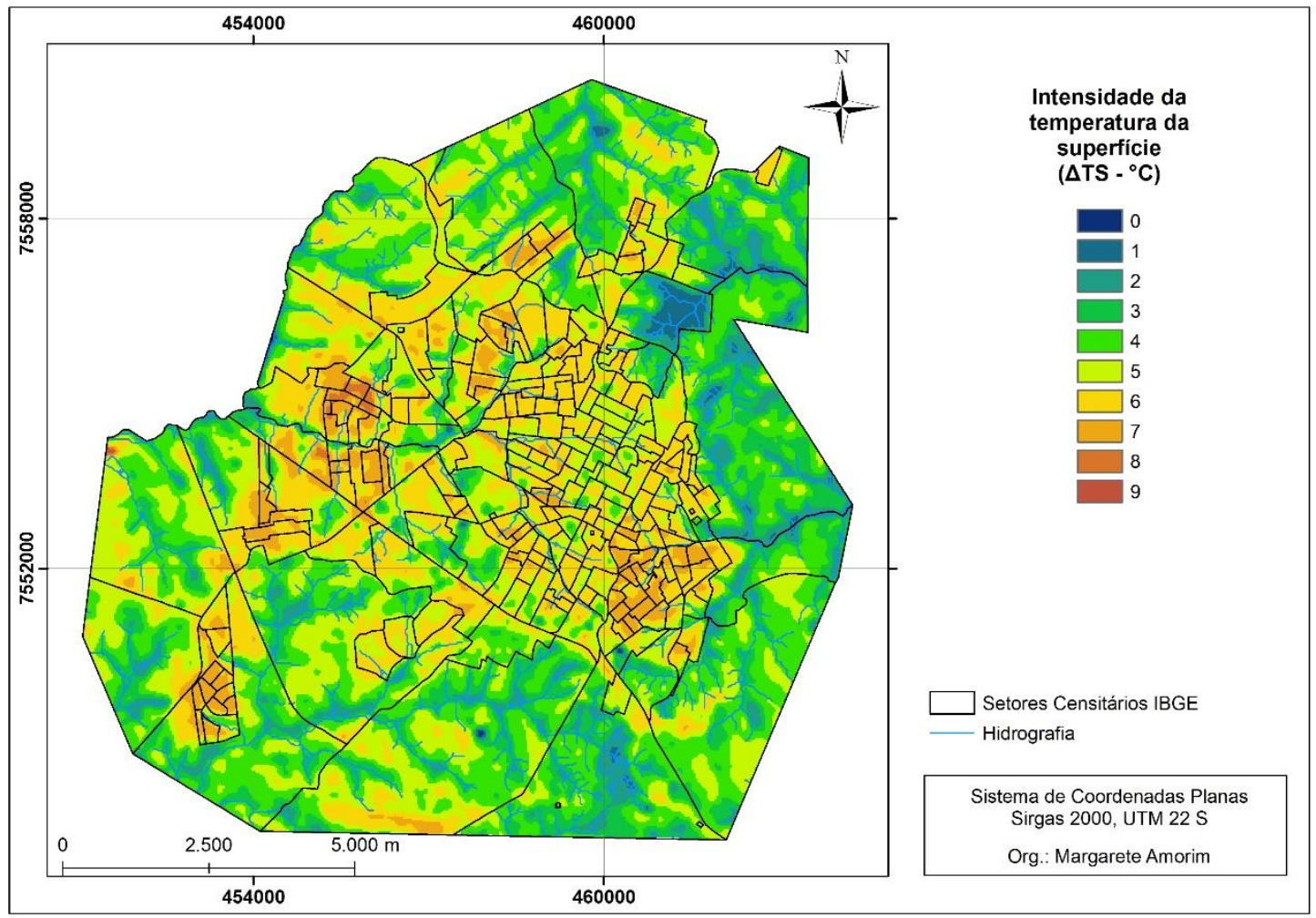

Figura 5. Presidente Prudente: distribuição espacial das intensidades das temperaturas superficiais média das 24 imagens do satélite Landsat 8, banda 10, de 2013 a janeiro de 2016 - 10h22 hora local. Fonte: elaborada pela autora (2018); imagens originais do satélite Landsat 8 adquiridas em http://earthexplorer.usgs.gov/ - WRS 222-075

Em estudo realizado por Amorim (2018) na mesma cidade, priorizou-se a análise das intensidades das temperaturas dos alvos, em relação aos sistemas atmosféricos predominantes nas estações do ano que proporcionaram as ocorrências de precipitações nos dias que antecederam as tomadas das imagens. Naquela análise, verificou-se que as áreas construídas não possuem altas magnitudes durante todos os períodos do ano. As maiores diferenças entre o urbano e o rural ocorreram durante os períodos em que as precipitações foram mais frequentes e intensas, especialmente quando bem distribuídas durante os 30 dias que antecederam a tomada das imagens. Isto ocorre porque a vegetação quando se apresenta mais vigorosa nas áreas rurais, diminuem as temperaturas nesses ambientes.

Este mesmo estudo também mostrou que sob condições atmosféricas que proporcionaram estabilidade e baixos totais de precipitação no período que antecedeu a tomada das imagens, houve diminuição da massa vegetal a partir da perda de parte das folhas da cobertura arbórea e exposição do solo devido à diminuição da cobertura vegetal rasteira, interferindo no balanço de energia - albedo, praticamente igualando as temperaturas dos alvos rurais aos urbanos (AMORIM, 2018). 
No presente artigo, ao se apresentar a síntese dos mapas das temperaturas dos alvos (Figura 4), por meio da média de cada pixel das 24 imagens registradas nas diferentes estações do ano ${ }^{5}$ (período seco e chuvoso), as ilhas de calor urbana superficiais atingiram magnitudes muito fortes exibindo grandes contrastes entre as temperaturas dos alvos rurais e urbanos, especialmente das áreas com alta densidade de cobertura vegetal arbórea e os bairros de baixo padrão construtivos e densamente edificados.

Outro aspecto a ser destacado é que os bairros mais antigos localizados nas áreas centrais da malha urbana e nos condomínios fechados de alto padrão construtivo, a maioria deles localizados na porção sul da malha urbana, mesmo que densamente construídos, apresentaram menores temperaturas dos alvos dos que os bairros populares de baixo padrão construtivo. Isto é consequência de os lotes serem maiores e preservarem algumas áreas permeáveis com vegetação, além da presença de vegetação arbórea nas calçadas e, em alguns casos, no interior dos lotes.

\section{CONSIDERAÇÕES FINAIS}

Este estudo mostrou que a variabilidade espacial das temperaturas das superfícies no ambiente urbano e rural próximo, resulta das características físicas dos alvos (tipos de materiais construtivos, impermeabilização do solo, densidade de construções e de vegetação).

Estas características, decorrentes do processo de urbanização, podem contribuir para que a população mais pobre e, portanto, mais vulnerável, seja mais suscetível a situações de desconforto térmico e sujeitas à problemas de saúde.

\footnotetext{
${ }^{5}$ As imagens tratadas do satélite Landsat 8, canal 10 (Ponto/órbita 222/075) foram capturadas nos dias: 01/05/2013; 18/06/2013; 21/08/2013; 06/09/2013; 22/09/2013; 09/11/2013;17/03/2014; 02/04/2014; 14/04/2014; 04/05/2014; 08/08/2014; 24/08/2014; 09/09/2014;11/10/2014; 30/12/2014; 15/01/2015; 31/01/2015; $07 / 05 / 2015 ; 23 / 05 / 2015 ; 08 / 06 / 2015 ; 11 / 08 / 2015 ; 14 / 10 / 2015 ; 30 / 10 / 2015 ; 18 / 01 / 2016$
} 
Neste sentido, o diagnóstico das temperaturas dos alvos, com o propósito de localizar as áreas da cidade onde são registradas temperaturas elevadas em relação às áreas rurais e vegetadas, pode contribuir para o estabelecimento de medidas para amenizá-las.

As imagens das temperaturas dos alvos geradas a partir das imagens do satélite Landsat 8 podem ser um importante instrumento para o diagnóstico das fontes de calor existentes nas superfícies, na medida em que a temperatura do ar resulta da interação entre a atmosfera e a superfície. Entretanto, análises simplistas que relacionam "causa e efeito" entre as temperaturas do ar e dos alvos, não se aplicam na realidade (AMORIM, 2017b).

Os eventos extremos de temperatura, associados às características das construções implicam em significativa vulnerabilidade da população. Torna-se, portanto, necessário o estabelecimento de políticas públicas e de construções de moradias menos vulneráveis diante das condições climáticas extremas, naturalmente registradas no ambiente tropical continental, em todas as estações do ano, como é o caso de Presidente Prudente.

Assim, fica evidente a necessidade de estudos do clima aplicados ao ordenamento do território e à promoção do conforto, da qualidade de vida e do bem-estar da população

\section{AGRADECIMENTOS}

A autora agradece à Fundação de Amparo à Pesquisa do Estado de São Paulo (FAPESP) - pelo financiamento de projeto de Auxílio à Pesquisa (2014/16350-3) e Acordo de Cooperação FAPESP/CNRS (2015/50439-4). Ao CNPq - Bolsa de Produtividade em Pesquisa - processo: $307287 / 2014-9$.

\section{REFERÊNCIAS}

AMORIM, M. C. C. T. Spatial variability and intensity frequency of surface heat island in a Brazilian city with continental tropical climate through remote sensing. Remote Sensing Applications: Society and Environment, Elsevier, 9, p. 10-16, 2018. 
AMORIM, M. C. C. T. Detecção remota de ilhas de calor superficiais: exemplos de cidades de porte médio e pequeno do ambiente tropical, Brasil. Finisterra, 105, p. 111-133, 2017a.

AMORIM, M. C. C. T. Teoria e método para o estudo das ilhas de calor em cidades tropicais de pequeno e médio porte. 2017b. 178 f. Tese (Livre-Docência). Faculdade de Ciências e Tecnologia, Universidade Estadual Paulista, Presidente Prudente/SP.

AMORIM, M. C. C. T. O clima urbano a partir do sensoriamento remoto e de registros da temperatura do ar. In: XIV Encuentro de Geógrafos da América Latina: reencuentro de saberes territoriales latinoamericanos. Anais... Lima/Peru: UGI, 2013, p. 1-18.

AMORIM, M. C. C. T. 0 clima urbano de Presidente Prudente/SP. 2000. 374f. Tese (Doutorado em Geografia) Faculdade de Filosofia, Letras e Ciências Humanas, Universidade de São Paulo, São Paulo.

AMORIM, M. C. C. T., DUBREUIL, V., QUENOL, H., SANT'ANNA NETO, J. L. Características das ilhas de calor em cidades de porte médio: exemplos de Presidente Prudente (Brasil) e Rennes (França). Confins (Paris), 7, p. 1-16, 2009.

AMORIM, M. C. C. T.; MONTEIRO, A. As temperaturas intraurbanas: exemplos do Brasil e de Portugal. Confins (Paris). 13, p. 1-18, 2011.

ANDRADE, L. L.; SOUZA, L. H.; SAKURAGI, J.; CASTRO, R. M. Estudo de ilhas de calor na cidade de São José dos Campos utilizando o canal infravermelho termal do Landsat-5 e o aerotransportado HSS. In: XIII Simpósio Brasileiro de Sensoriamento Remoto, Santa Catarina, Anais... Florianópolis: INPE, 2007, p. 473-480.

ARAUJO, T. L.; DI PACE, F. T. Valores instantâneos da temperatura da superfície terrestre na cidade de Maceió-AL utilizando imagens do satélite TM/Landsat 5. Revista Brasileira de Geografia Física. v.3 n.2, p. 104-111, 2010.

ARAUJO, E. D. S.; SILVA, J. B.; MACHADO, C. C. C. Identificação de Ilhas de Calor na Cidade de Campina Grande-PB utilizando Sensoriamento Remoto. Revista Brasileira de Geografia Física. V.9 n.2, p. 614-626, 2016.

ARNFIELD, A. J. Two decades of urban climate research: a review of turbulence, exchanges of energy and water, and the urban heat island. International Journal of Climatology. V.23 n.1, p. 1-26, 2003.

BARBOSA, R. V. R; VECCHIA, F. A. S. Estudos de ilha de calor urbana por meio de imagens do Landsat 7 Etm+: estudo de caso em São Carlos (SP). Revista Minerva. V.6 n.3, p. 273-278, 2009.

BARROS, H. R.; LOMBARDO, M. A. A Relação entre ilhas de calor urbana, ocupação do solo e morfologia urbana na cidade do Recife. Revista Geonorte. Edição Especial 2, p. 65-76, 2012.

BIAS, E. S.; BAPTISTA, G. M. M. A análise do fenômeno de ilhas de calor urbanas, por meio da combinação de dados Landsat e Ikonos. In: XI Simpósio Brasileiro de Sensoriamento Remoto. Anais..., 2003, p. 1741-1748.

CARDOSO, R. S. Classificação de potenciais unidades climáticas em Presidente Prudente-SP. 2015. Dissertação (Mestrado em Geografia) - Universidade Estadual Paulista Júlio de Mesquita Filho, Presidente Prudente.

COLL, M.; PIRODDI, C.; STEENBEEK, J.; KASCHNER, K.; BEN RAIS LASRAM, F.; AGUZZI, J.; et al. The biodiversity of the Mediterranean Sea: estimates, patterns, and threats. PLoS ONE. V.5 n.8, p. 1-36, 2010.

COLTRI, P. P.; VELASCO, G. D. N.; POLIZEL, J. L.; DEMÉTRIO, V. A.; FERREIRA, N. J. Ilhas de calor da estação de inverno da área urbana do município de Piracicaba, SP. In: XIII Simpósio Brasileiro de Sensoriamento Remoto, Santa Catarina, Anais... Florianópolis: INPE, 2007, p. 5151-5157. 
CRUZ, G. C. F. Clima urbano de Ponta Grossa - PR: uma abordagem da dinâmica climática em cidade média subtropical brasileira. 2009. Tese (Doutorado em Geografia), Faculdade de Filosofia, Letras e Ciências Humanas, Universidade de São Paulo, São Paulo.

DORIGON, L. P.; AMORIM, M. C. C. T. Estrutura térmica da superfície de Paranavaí/PR através do Landsat 7. Caderno Prudentino de Geografia. N. 2, p. 110-129, 2013.

FEITOSA, S. M. R.; GOMES, J. M. A.; MOITA NETO, J. M.; ANDRADE, C. S. P. Consequências da urbanização na vegetação e na temperatura da superfície de Teresina - Piauí. Revista da Sociedade Brasileira de Arborização Urbana. N.6, p. 58-75, 2011.

GALLO, K. P.; McNAB, A. L.; KARL, T. R.; BROWN, J. F.; HOOD, J. J.; and TARPLEY, J.D. The Use of NOAA AVHRR Data for Assessment of the Urban Heat Island Effect. Center for Advanced Land Management Information Technologies--Publications. 1. http://digitalcommons.unl.edu/calmitpapers/1, 1993.

IBGE-Instituto Brasileiro de Geografia e Estatística. Cidades. Disponível em: https://cidades.ibge.gov.br/ Acesso em: 27 jul. 2018.

KIDDER, S. Q.; WU, H. T. A multispectral study of the St.Louis area under snow-covered concitions using NOAA-7 AVHRR data. Remote sensing of environment. V.22 n.2, p. 159-172, 1987.

LEMOS, J. S. Espacialização da Ilha de Calor do Aglomerado Urbano da Região Metropolitana de Curitiba (AU-RMC) em Agosto de 2006 a Partir de Termografia de Superfície. In: XV Simpósio Brasileiro de Sensoriamento Remoto. Anais... Curitiba: INPE, 2011, p. 4271-4278.

LOMBARDO, M. A. Ilha de calor nas metrópoles: o exemplo de São Paulo. São Paulo, 1985.

LUCEnA, A. J.; ROTUNnO FIlHO, O. C.; ALMEIDA FRANÇA, J. R.; FARIA PERES, L.; XAVIER, L. N. R. Urban climate and clues of heat island events in the metropolitan area of Rio de Janeiro. Theoretical and applied climatology. V.111 n.3-4), p. 497-511, 2013.

MATSON, M.; McCLAIN, E. P.; McGINNIS, D. F. Jr.; PRITCHARD, J. A. Satellite Detection of Urban Heat Islands. Monthly Weather Review. 106, p. 1725-1734, 1978.

MENDONÇA, F. de A. 0 clima e o planejamento urbano de cidade de porte médio e pequeno: proposição metodológica para estudo e aplicação à cidade de Londrina, PR. 1994. 322f. Tese (Doutorado em Geografia Física) - Faculdade de Filosofia, Letras e Ciências Humanas, Universidade de São Paulo, São Paulo.

MENDONCA F.; DUBREUIL V. Termografia de superfície e temperatura do ar na RMC (Região Metropolitana de Curitiba - PR). Revista RA'E GA - 0 espaço geográfico em análise, n. 9, p. 25-35, 2005.

OKE, T. R. Boundary Layer Climates. London: Methuem \& Ltd. A. Halsted Press Book, John Wiley \& Sons, New York, 1978.

ORTIZ, G. F.; AMORIM, M. C. C. T. Índice de vegetação por diferença normalizada (NDVI), temperatura da superfície e do ar na cidade de Tarumã/SP. In: XIV Encuentro de Geógrafos de América Latina: reencuentro de saberes territoriales latinoamericanos. Anais... Lima/Peru: UGI. 2013, p. 1-20.

POLIZEL, J. L. Geotecnologias e clima urbano: aplicação dos recursos de sensoriamento remoto e sistema de informações geográficas na cidade de Piracicaba, SP. São Paulo. 2009. Tese (Doutorado em Geografia) - Faculdade de Filosofia, Letras e Ciências Humanas, Universidade de São Paulo. 
SOUSA, D. O.; BAPTISTA, G. M. M. Análise da influência da resolução espacial na determinação das ilhas urbanas de calor em São Paulo, por meio dos sensores ASTER e MODIS. In: XII Simpósio Brasileiro de Sensoriamento Remoto. Anais... Goiás: INPE, 2005, p. 4525-4530.

SPOSITO, E. S. Presidente Prudente: crítica da formação histórica. In: WHITACKER, A. M.; MELAZZO, E. S. (coord.) Conjuntura Prudente 2011. Presidente Prudente, FCT/UNESP, 2011.

UGEDA JUNIOR, J. C. Correlação entre a temperatura da superfície e temperatura do ar na cidade de Jales-SP. In: AMORIM, M. C. C. T.; SANT'ANNA NETO, J. L.; MONTEIRO, A. (Org.). Climatologia Urbana e Regional: questões teóricas e estudos de caso. São Paulo: Outras Expressões. 1, 2013, p. 291-316.

WENG, Q. Fractal analysis of satellite-detected urban heat island effect. Photogrammetric engineering \& remote sensing. V. 69 n.5, p. 555-566, 2003. 